\title{
Peran Conscientiousness sebagai Moderator dari Hubungan Job Resources dan Work Engagement Karyawan Information Technology (IT) pada PT. X
}

\author{
Winoto Sugiarto ${ }^{1}$, P. Tommy Y. S. Suyasa ${ }^{2}$ dan Daniel Lie $^{3}$ \\ ${ }^{1}$ Program Studi Magister Psikologi, Universitas Tarumanagara Jakarta \\ Email: winotosugiarto.lie@gmail.com \\ ${ }^{2}$ Program Studi Magister Psikologi, Universitas Tarumanagara Jakarta \\ Email: sumatera.suyasa@gmail.com \\ ${ }^{3}$ Program Studi Magister Psikologi, Universitas Tarumanagara Jakarta \\ Email: danielsugiantolie@gmail.com
}

\begin{abstract}
ABSTRAK
Penelitian ini bertujuan untuk melihat peran dari conscientiousness sebagai moderator hubungan antara job resources dan work engagement yang ada pada PT. X khususnya pada unit kerja Information Technology (IT). Karyawan IT yang bekerja menunjukkan work engagement yang rendah, indikatornya adalah semangat, dedikasi dan kekhusyukan yang rendah terhadap pekerjaan. Partisipan diambil dari 72 karyawan IT yang terdiri dari developer dan support di PT. X. Teknik sampling menggunakan probability sampling. Pengambilan data dilakukan dengan cara menyebarkan kuesioner Utrecht Work Engagement Scale (UWES), Job-Demands Resources Questionnaire, dan NEO PI. Hasil penelitian menunjukkan bahwa job resources berelasi positif terhadap work engagement. Relasi positif antara job resources dan work engagement tidak berbeda antara partisipan yang memiliki conscientiousness tinggi dan partisipan yang memiliki conscientiousness rendah pada dimensi coaching dan opportunity for development. Namun peran conscientiousness sebagai moderator hubungan antara job resources dan work engagement terlihat pada dimensi feedback, social support dan autonomy.
\end{abstract}

Keywords: work engagement, job resources, conscientiousness, moderator, karyawan IT

\section{PENDAHULUAN}

Penelitian di bidang psikologi terapan dan sumber daya manusia menunjukkan bahwa investasi dalam human capital dapat menghasilkan individu yang positif serta hasil kinerja yang baik dalam level organisasi (Becker \& Huselid, 2006; Bowen \& Ostroff, 2004; Huselid, 1995; Le, Oh, Shaffer, \& Schmidt, 2007; Subramony, Krause, Norton, \& Burns, dalam Crook, Combs, Todd, \& Whoer, 2011). Keberadaan human capital saat ini menjadi aset penting bagi perusahaan. Human capital merujuk pada pengetahuan, keahlian, dan kemampuan yang ada dalam diri seorang karyawan (Coff, 2002, dalam Crook, et al., 2011). Karyawan mempunyai peranan penting dalam menggerakkan bisnis perusahaan. Perusahaan yang menyadari peran tersebut akan melakukan upaya untuk mengembangkan karyawan yang bekerja di dalamnya. Sebagai contoh pengembangan dilakukan melalui pelatihan dan pembinaan. Dengan melakukan pengembangan karyawan ini, sesuai dengan hasil penelitian yang dilakukan oleh Crook, et al. (2011) bahwa investasi pada human capital mempunyai pengaruh positif terhadap individu (karyawan) dan organisasi yang ditandai dengan kinerja yang baik.

PT. X adalah perusahaan yang bergerak di sektor perbankan. PT. X berdiri sejak tahun 1955 . PT. $\mathrm{X}$ merupakan perusahaan swasta yang berperan sebagai payment bank. Payment bank adalah bank yang berperan sebagai penyedia jasa pembayaran yang harus dilakukan baik oleh nasabah individu maupun perusahaan. Produk yang dihasilkan PT. X bukan hanya tabungan, tetapi ada fasilitas pembayaran dan supply chain management dari perusahaan yang bekerja sama. Untuk mendukung produk jasa tersebut, diperlukan sistem yang mendukung. PT. X memandang bahwa sistem adalah suatu hal yang sangat penting untuk mewujudkan layanan yang baik untuk nasabah. Oleh sebab itu, PT. X juga sangat memperhatikan sumber daya manusia yang mengembangkan sistem tersebut. Unit kerja yang berperan untuk membuat sistem dan mendukung ketersediaan sistem tersebut adalah Grup Strategic Information and Technology. 
Grup tersebut dibagi menjadi dua sub grup, yaitu grup infrastructure and support, serta application development.

Di PT. X, pada khususnya unit kerja Information Technology (IT), ditemukan beberapa kejadian yang menunjukkan work engagement tidak terlalu tinggi dari karyawan. Keterikatan kerja dapat diartikan sebagai pemikiran hubungan kerja yang mempunyai ciri semangat, dedikasi, dan kekhusyukan. Soennentag, Demerouti, Mojza dan Bakker (2012) menjelaskan ketiga ciri tersebut sebagai berikut, semangat (vigor) dan mental yang tangguh saat bekerja dan mempunyai usaha yang tulus dan mampu bertahan dalam kesulitan. Dedikasi (dedication) berarti antusias dan terinspirasi di tempat kerja serta mengalami signifikansi, kebanggaan, dan tantangan. Kekhusyukan (absorption) dapat digambarkan sebagai konsentrasi penuh di tempat kerja dan sebagai pengalaman yang membahagiakan dalam karyawan. Schaufeli dan Bakker (2004) menuliskan work engagement sebagai suatu hal yang positif, terpenuhi, suatu keadaan pikiran yang dikarakteristikkan sebagai semangat, dedikasi, dan kekhusyukan.

Semangat (vigor) yang merupakan salah satu dimensi work engagement dapat terlihat pada keseharian karyawan. Pada unit kerja IT, semangat karyawannya rendah. Ciri yang ditunjukkan adalah kurang bersemangat pada pagi hari. Begitu sampai di meja kerja, tidak langsung menyiapkan jadwal kegiatan pada hari tersebut, namun lebih banyak melamun, membereskan meja kerja dengan malas-malasan, mengambil sarapan atau menyiapkan kopi di pagi hari pun dilakukan dengan malas dan berlama-lama.

Bukan hanya pada pagi hari, namun pada saat aktivitas pada siang atau sore hari seperti saat meeting project dan diskusi dalam kelompok, semangat yang rendah juga tercermin pada sikap karyawan IT yang mengikutinya. Pada saat diskusi, diharapkan semua karyawan yang ada di dalamnya berpartisipasi untuk melakukan brainstorming, membahas tentang suatu topik, dengan harapan dapat membuahkan hasil yang mengacu pada tujuan yang ingin dicapai. Namun jika ada partisipan yang ternyata bermalas-malasan untuk berpikir dan bahkan berpartisipasi dalam kegiatan meeting terserbut. Akibatnya ketidak ikut sertaan karyawan tersebut bisa mengganggu proses diskusi yang bisa berpotensi tidak mebuahkan hasil apa-apa dari diskusi tersebut.

Dimensi lain dari work engagement yang terlihat pada aktivitas sehari-hari karyawan IT di PT. X adalah dedikasi (dedication). Dedikasi adalah keterlibatan yang kuat dalam pekerjaan seseorang, disertai dengan perasaan antusiasme dan tantangan di tempat kerja (Schaufeli \& Bakker, 2014). Schaufeli dan Bakker (2010) menyatakan bahwa dedikasi mengacu pada keterlibatan seseorang yang sangat tinggi terhadap suatu pekerjaan.

Salah satu contoh fenomena terkait dimensi dedikasi yang terjadi pada lingkungan kerja IT adalah beberapa karyawan menunjukkan gejala bahwa pekerjaan yang mereka lakukan tidak menantang bagi mereka. Bahkan ada yang merasa bahwa pekerjaan yang dilakukannya tidak berarti karena atasan tidak memberikan dia kebebasan untuk berkreasi atas apa yang harus dikerjakan. Akibatnya karyawan tersebut merasa bahwa tidak ada artinya mengerjakan pekerjaan tersebut, dan tidak merasa antusias ketika diberikan penugasan.

Contoh fenomena lain yang terjadi di lingkungan kerja IT terkait dengan kekhusyukan adalah begitu mudahnya karyawan untuk lepas dari pekerjaan yang sedang dilakukannya. Bukan hanya karena gangguan yang berupa pekerjaan lain, namun juga hal-hal kecil yang tidak ada hubungannya dengan pekerjaan. Kejadian tersebut perlu dikaji apakah memang nilai 
kekhusyukan dari karyawan memang rendah. Ketiga fenomena tersebut mewakili dari dimensidimensi work engagement.

Penelitian terbaru dilakukan oleh Virga, Horga dan Iliescu (2015) mengenai hubungan antara job resources dengan work engagement. Peneliti menggunakan work-life imbalance (WLI) sebagai moderator terhadap hubungan tersebut. Dalam penelitian tersebut, peneliti juga melakukan pengujian terhadap hipotesis dari $J D-R$ model, yang pertama yaitu job demands sebagai moderator hubungan antara resources (job resources dan personal resource) dan work engagement. Kedua, konsep Work-Life Imbalance (WLI) yang dapat digunakan sebagai pengganti job demands. Akibatnya Virga, et al. (2015) terdorong untuk menjadikan WLI sebagai moderator yang melemahkan hubungan antara resources dengan work engagement.

WLI didefinisikan sebagai suatu bentuk dari konflik yang tekanannya berasal dari area keluarga dan pekerjaan yang saling bertentangan (Greenhaus \& Beutell, 1985). WLI mempunyai hubungan yang negatif terhadap dimensi work engagement, khususnya vigor (Halbesleben, 2010). Hasil dari penelitian Virga, et al. (2015) menunjukkan WLI sebagai moderator yang melemahkan hubungan antara job resources dan work engagement adalah tidak signifikan. Selain itu, Virga, et al. (2015) pada diskusi keterbatasan penelitian memberikan saran pada penelitian selanjutnya agar menggunakan personal resource yang lain untuk melakukan penelitian, karena pada penelitian ini ditemukan hasil yang berbeda dengan penelitian sebelumnya yang pernah ada.

Penelitian lain yang dilakukan oleh Xanthopoulou, Bakker, Demerouti, dan Schaufeli (2007), personal resource seperti optimism, self-efficacy dan organizational-based self-esteem ditemukan sebagai prediktor dari work engagement. Selain personal resource tersebut, masih ada penelitian lain yang menunjukkan bahwa tiga dari lima dimensi kepribadian berhubungan dengan work engagement yaitu emotional stability (yang tinggi), extroversion (yang tinggi), dan conscientiousness (yang tinggi) (Bakker, 2010; Grant \& Langan-Fox, 2007; Kim, Shin, \& Swanger, 2009).

Pada penelitian yang dilakukan oleh Jeong, Jeong, Hyun dan Swanger (2009) menunjukkan bahwa work engagement dipengaruhi oleh kepribadian. Kepribadian yang paling menonjol dalam mempengaruhi work engagement adalah conscientiousness. Conscientiousness berpengaruh positif terhadap work engagement. Orang dengan nilai conscientiousness tinggi akan mempunyai nilai work engagement yang tinggi juga. Conscientiousness yang merupakan salah satu dimensi kepribadian menunjukkan hubungan positif yang kuat terhadap work engagement (Opie \& Henn, 2013). Penelitian yang dilakukan oleh Jeong et al. (2009) dalam the effects of personality and work engagement ditemukan hubungan antara conscientiousness tinggi terhadap work engagement yang tinggi.

Didukung oleh penelitian yang dilakukan oleh Opie dan Henn (2013) serta melanjutkan saran yang diberikan oleh Virga, et al. (2015), peneliti melakukan penelitian dengan hipotesis: Conscientiousness merupakan moderator dari hubungan Job Resources dan Work Engagement.

\section{METODE PENELITIAN}

Partisipan diambil dari populasi karyawan IT yang ada di PT. X. Peneliti mengambil partisipan sebanyak 72 orang. Berdasarkan jenis kelamin, jumlah partisipan laki-laki ada 42 orang $(58,3 \%)$ dan jumlah partisipan perempuan ada 30 orang (41,7\%). Penelitian menggunakan metode kuantitatif dan non experimental. Peneliti menggunakan tiga variabel yaitu work engagement, 
job resources, dan personality. Peneliti menyebarkan kuesioner untuk diisi oleh partisipan. Teknik sampling yang digunakan dalam penelitian ini adalah purposive sampling karena pengambilan sampel dilakukan pada karyawan IT saja pada PT. X. Teknik analisis dilakukan dengan analisis korelasional antara ketiga variabel Pertama diawali dengan menghitung korelasi antara job resources dengan work engagement, kemudian menambahkan conscientiousness sebagai moderator dalam relasi hubungan job resources dan work engagement.

Work engagement diukur dengan menggunakan Utrecht Work Engagement Scale (UWES). Butir yang digunakan sebanyak 17. Dimensi yang diukur adalah vigor, dedication dan absorption. UWES diciptakan oleh Schaufeli dan Bakker pada tahun 2003. Contoh butir dari UWES antara lain "Saya merasa bersemangat ketika bekerja" (Vigor); "Saya merasa pekerjaan yang saya lakukan memiliki makna dan manfaat yang jelas" (Dedication); dan "Ketika bekerja saya merasa waktu berlalu begitu cepat" (Absorption). Hasil uji reliabilitas dari work engagement terbukti dengan Cronbach's Alpha $0.834>0.482$ (nilai dari tabel distribusi dengan level signifikansi 5\%). Bukti criterion validity ditunjukkan dengan pengetesan alat ukur tersebut dengan menggunakan 4 criterion (Biggs, Brough \& Barbour, 2014). Construct validity dari UWES ditunjukkan dengan nilai CFI=0,91 analisis 3 faktor (Schaufeli \& Bakker, 2003).

Job Resources diukur dengan menggunakan The Job Demands-Resources Questionnaire yang dibuat oleh Bakker (2014). Dimensi yang diukur dalam kuesioner tersebut adalah work pressure, cognitive demands, emotional demands, role conflict, hassles (job demands); autonomy, social support, feedback, opportunities for development, coaching (job resources). Contoh butir yang digunakan sebagai alat ukur job demands-resources antara lain "Apakah Anda mempunyai keleluasaan dalam cara/metode mengerjakan tugas Anda?" (Autonomy); "Dalam pekerjaan Anda, apakah Anda merasa dihargai oleh rekan kerja Anda?" (Social Support); "Saya menerima informasi (umpan balik) yang bermanfaat, tentang kualitas hasil pekerjaan saya" (Feedback); "Saya merasa dihargai oleh atasan saya" (Coaching); dan "Project-project yang saya kerjakan menawarkan hal baru untuk saya pelajari" (Opportunity for Development). Hasil uji reliabilitas dari job resources terbukti dengan Cronbach's Alpha $0.886>0.456$ (nilai dari tabel distribusi dengan level signifikansi 5\%). Construct validity dari JD-R questionnaire menunjukkan nilai $\mathrm{CFI}=0,94, \mathrm{NFI}=0,93$ (Bakker, Demerouti, Taris, Schaufeli, \& Schreurs, 2003).

Kepribadian diukur dengan menggunakan NEO-PI 60-butir yang dikembangkan oleh Costa dan McCrae (1989). Dimensi yang diukur sesuai dengan Five-Factor Models, yaitu Neuroticism, Extraversion, Openness, Conscientiousness, dan Agreeableness. Contoh butir alat ukur yang positif digunakan antara lain "Saya suka menentukan prioritas mengenai hal yang akan saya kerjakan" (Conscientiousness). Contoh butir alat ukur negatif antara lain "Sebenarnya saya seringkali harus mempersiapkan diri dalam menghadapi ujian, namun sayang saya seringkali mengabaikannya" (Conscientiousness). Hasil uji reliabilitas dari conscientiousness terbukti dengan Cronbach's Alpha $0.824>0,576$ (nilai dari tabel distribusi dengan level signifikansi 5\%).

\section{HASIL DAN PEMBAHASAN}

Dalam melakukan analisis korelasi hubungan ketiga variabel peneliti melakukan beberapa langkah untuk mendapatkan hasilnya. Langkah 1 untuk melihat peran job resource terhadap work engagement. Peneliti melakukan konversi nilai mentah dari masing-masing variabel ke $\mathrm{z}$ score, kemudian meregresikan $\mathrm{z}$ score job resource dengan $\mathrm{z}$ score work engagement. Hasil dari nilai regresi kedua variabel tersebut adalah $\mathrm{R}=0.562, \mathrm{p}=0.000, \beta=0.562$; yang artinya job resources mempunyai peran terhadap nilai work engagement. 
Selanjutnya dari perhitungan nilai regresi diperoleh nilai $\mathrm{R}=0.562$, koefisien determinasi $\mathrm{R}^{2}=0.316$. Nilai tersebut menunjukkan bahwa varians dari variabel job resource yang mempengaruhi work engagement adalah sebesar 31,6\%. Selain itu, terdapat $68,4 \%$ (100\%$31,6 \%$ ) varians work engagement dijelaskan oleh faktor yang lain.

Langkah 2 melihat apakah job resources dan conscientiousness mempunyai peran terhadap work engagement. Peneliti menghitung regresi dari z score variabel job resources dan $\mathrm{z}$ score dari variabel conscientiousness sebagai prediktor dari work engagement. Hasil dari regresi ketiga variabel tersebut adalah $\mathrm{R}=0,618, \mathrm{p}=0,000, \beta(\mathrm{z}$ score job resources $)=5,33, \beta(\mathrm{z}$ score conscientiousness $)=0,257$, yang artinya job resource dan conscientiousness mempunyai peran positif terhadap work engagement.

Berdasarkan perhitungan nilai regresinya, diperoleh nilai $\mathrm{R}=0,618$, koefisien determinasi $\mathrm{R}^{2}=0,382$. Nilai tersebut menunjukkan bahwa varians dari variabel job resources dan conscientiousness yang mempengaruhi work engagement adalah sebesar 38,2\%. Faktor lain yang dapat menjelaskan varians dari work engagement adalah sebesar $61,8 \%(100 \%-38,2 \%)$.

Langkah 3 menambahkan variabel conscientiousness sebagai moderator dari hubungan antara job resources dan work engagement. Hasil dari perhitungan menunjukkan bahwa nilai $\mathrm{R}=0,622, \mathrm{p}=0,000, \beta(\mathrm{z}$ score job resources $)=0,547, \beta(\mathrm{z}$ score conscientiousness $)=0,270, \beta(\mathrm{z}$ score JR X C)=-0,074. Pada perhitungan langkah 3 ini, didapatkan bahwa conscientiousness tidak signifikan sebagai moderator, nilai signifikasi $0,459>0,05$.

Langkah 4 menguji hubungan antara dimensi job resources dan work engagement dengan kondisi conscientiousness tinggi dan rendah. Pada dimensi feedback, didapatkan hasil bahwa conscientiousness menjadi moderator dari hubungan antara feedback (job resources) dan work engagement. Pada conscientiousness yang rendah adanya feedback akan berpengaruh terhadap work engagement $(\mathrm{sign}=0,012, \beta=0,405)$. Sedangkan dalam kondisi conscientiousness tinggi, feedback tidak mempengaruhi work engagement $(\operatorname{sign}=0,246, \beta=0,208)$.

Pada dimensi coaching, conscientiousness tidak menjadi moderator dari hubungan coaching (job resources) terhadap work engagement. Conscientiousness yang tinggi maupun rendah coaching akan tetap berpengaruh pada work engagement seseorang. Pada conscientiousness rendah, nilai hubungan antara coaching dan work engagement menunjukkan sign $=0,001, \beta=0,516$ dan pada conscientiousness tinggi, menunjukkan nilai sign $=0,005, \beta=0,480$.

Pada dimensi social support, conscientiousness berperan sebagai moderator dari hubungan antara social support (job resources) dan work engagement. Pada conscientiousness rendah, social support berpengaruh terhadap work engagement dengan nilai sign $=0,001, \beta=0,500$. Sedangkan pada conscientiousness tinggi, social support tidak berpengaruh secara signifikan terhadap work engagement $(\operatorname{sign}=0,076, \beta=0,313)$.

Pada dimensi opportunity for development, conscientiousness tidak berperan sebagai moderator dari hubungan opportunity for development (job resources) dan work engagement. pada conscientiousness rendah maupun tinggi, hubungan antara opportunity for development dan work engagement tetap signifikan. Pada conscientiousness rendah, nilai hubungan antara opportunity for development dan work engagement menunjukkan sign $=0,000, \beta=0,540$ dan pada conscientiousness tinggi, menunjukkan nilai sign $=0,006, \beta=0,466$. 
Pada dimensi terakhir dari job resources, autonomy, conscientiousness berperan sebagai moderator dari hubungan antara autonomy (job resources) dan work engagement. pada conscientiousness rendah, autonomy berpengaruh terhadap work engagement (sign $=0,007$, $\beta=0,428$ ). sedangkan pada conscientiousness yang tinggi, autonomy tidak berpengaruh secara signifikan terhadap work engagement $(\operatorname{sign}=0,05, \beta=0,344)$.

Menurut Schaufeli dan Bakker (2004) menyebutkan bahwa job resources mempunyai pengaruh positif terhadap work engagement. Dalam penelitian ini terbukti bahwa karyawan dengan job resource tinggi akan mempunyai nilai work engagement yang tinggi. Dimensi dari job resource seperti autonomy dan social support mempunyai pengaruh terhadap dimensi dari work engagement secara tidak langsung melalui motivasi yang terdorong karena tercipta kondisi kerja yang positif. Hal tersebut menyebabkan karyawan merasa positif yang ditandai dengan semangat, dedikasi, dan kekhusyukan yang ketiganya merupakan dimensi dari work engagement. Conscientiousness, dengan kata lain sungguh-sungguh dalam melakukan tugas, bertanggung jawab, dapat diandalkan, dan menyukai keteraturan dan kedisiplinan (Goldbert, 1981). Pada penelitian kali ini, ciri conscientiousness tidak mempunyai pengaruh yang dapat memperkuat atau memperlemah hubungan antara job resources dan work engagement. Menurut peneliti, ketika seseorang dengan conscientiousness tinggi, yang artinya orang tersebut teratur dan sangat hati-hati. Conscientiousness akan menjadi moderator dari hubungan antara job resources dan work engagement ketika autonomy diberikan disertai dengan adanya kesempatan untuk mengendalikan situasinya, maka orang tersebut dapat lebih terlarut dalam pekerjaannya. Hal ini sesuai dengan hasil penelitian yang dilakukan oleh Bakker, Demerouti dan Brummelhuis (2012).

Namun pada penelitian ini, didapatkan bahwa conscientiousness tidak berperan sebagai moderator pada hubungan antara job resources dan work engagement pada dimensi job resources tertentu. Khususnya pada dimensi coaching dan opportunity for development. Artinya seseorang yang conscientiousness tinggi maupun rendah, coaching maupun opportunity for development yang diberikan pada mereka akan tetap berpengaruh pada work engagement yang dimiliki oleh orang tersebut. Work engagement akan tetap naik ketika coaching dan opportunity for development tersebut diberikan. Dalam penelitian ini, conscientiousness akan menjadi moderator hubungan antara job resources dan work engagement pada dimensi feedback, social support dan autonomy. Pada orang dengan nilai conscientiousness rendah, ada atau tidaknya feedback mempengaruhi nilai work engagement orang tersebut. Pada orang dengan nilai conscientiousness tinggi, ada atau tidaknya feedback tidak terlalu berpengaruh pada nilai work engagement orang tersebut. Dimensi social support dan autonomy pada job resources yang akan lebih berperan mempengaruhi work engagement ketika conscientiousness rendah.

\section{KESIMPULAN}

Dalam penelitian kali ini ditemukan bahwa conscientiousness berperan sebagai moderator dalam hubungan antara job resources dan work engagement pada dimensi feedback, social support dan autonomy. Sesuai pada hasil penelitian yang dilakukan oleh Bakker, et al. (2012) yang menunjukkan bahwa conscientiousness dapat berperan sebagai moderator dalam hubungan antara work engagement, performance dan active learning. Dalam penelitian ini conscientiousness pun berperan sebagai moderator dari hubungan antara job resources dan work engagement. Diharapkan pada penelitian selanjutnya dapat menggunakan partisipan dengan karakteristik kerja yang sama (sebagai contohnya karyawan IT) namun di beberapa perusahaan yang berbeda untuk menambah varians. Ide lain yang berisi saran topik yang menggunakan penelitian ini sebagai referensi. Dalam penelitian kali ini, peneliti belum memasukkan variabel 
job demands. Secara karakteristik sangat berbeda dengan job resources karena job demands dapat menurunkan nilai dari work engagement (Schaufeli \& Bakker, 2004).

\section{Ucapan terima kasih}

Terima kasih kami ucapkan kepada PT X yang mengijinkan kami untuk mengambil data. Terima kasih juga kami ucapkan untuk seluruh partisipan dan bagian manajemen IT, Bapak Fransiscus, Bapak Iman, dan Bapak Chandra atas ijin yang diberikan kepada kami untuk melakukan pengambilan data.

\section{REFERENSI}

Bakker, A.B. (2014). The job demands-resources questionnaire. Rotterdam: Erasmus University.

Bakker, A. B., \& Leiter M. P. (2010). Work engagement: A handbook of essential theory and research. England: Psychology Press.

Bakker, A. B., Demerouti, E., Brummelhuis, L. L. (2012). Work engagement, performance and active learning: The role of conscientiousness. Journal of Vocational Behavior, 80, 555564.

Bakker, A. B., Demerouti, E., Taris, T. W., Schaufeli, W. B., \& Schreurs, P. J. G. (2003). A multigroup analysis of job demands-resources model in four home care organizations. International Journal of Stress Management, 10, 16-38.

Becker, B. E., \& Huselid, M. A. (2006). Strategic human resource management: Where do we go from here? Journal of Management, 32, 898-925. doi:10.1177/0149206306293668

Biggs, A., Brough, P., \& Barbour, J. P. (2014). Enhanching work-related attitudes and work engagement. International Journal of Stress Management, 21, 43-68.

Bowen, D. E., \& Ostroff, C. (2004). Understanding HRM-firm performance linkages: The role of "strength" of the HRM system. Academy of Management Review, 29, 203-221. doi:10.2307/20159029

Crook, T. R., Combs, J. G., Todd, \& Whoer, D. J. (2011). Does human capital matter? A metaanalysis of the relatiohship between human capital and firm performance. Journal of Applied Psychology, 96(3), 443-456.

Coff, R. W. (2002). Human capital, shared expertise, and the likelihood of impasse on corporate acquisitions. Journal of Management, 28, 107-128. doi:10.1177/014920630202800107

Greenhaus, J. H., \& Beutell, N. J. (1985). Sources of conflict between work and family roles. Academy of Management Review, 10, 76-88.

Halbesleben, J. R. B. (2010). A meta-analysis of work engagement: relationships with burnout, demands, resources and consequences. In A. B. Bakker \& M. P. Leiter (Eds.), Work engagement: A handbook of essential theory and research (pp. 102-117). New York, NY: Psychology Press.

Jeong, H., Hyun, K., \& Swanger, N. (2009). Burnout and engagement: A comparative analysis using the Big Five personality dimensions. International Journal of Hospitality Management, 28, 96-104. http://dx.doi.org/10.1016/j.ijhm.2008.06.001

Kim, H. J., Shin, K. H., \& Swanger, H. (2009). Burnout and engagement: A comparative analysis using the Big Five personality dimensions. International Journal of Hospitality Management, 28, 96-104.

Langelaan, S., Bakker, A.B., van Doornen, L.J.P., \& Schaufeli, W.B. (2006). Burnout and work engagement: do individual differences make a difference? Personality and Individual Differences, 40, 521-532. 
Le, H., Oh, I. S., Shaffer, J., \& Schmidt, F. (2007). Implications of methodological advances for the practice of personnel selection: How practitioners benefit from meta-analysis. Academy of Management Perspectives, 21, 6-15.

Opie, T. J., \& Henn, C. M. (2013). Work-family conflict and work engagement among mothers: conscientiousness and neuroticism as moderators. SA Journal of Industrial Psychology, $39(1)$.

Schaufeli, W. B., \& Bakker, A. B. (2003). Utrecht work engagement scale. Utrecht University.

Schaufeli, W. B., \& Bakker, A. B. (2004). Job demands, job resources, and their relationship with burnout and engagement: A multi-sample study. Journal of Organizational Behavior, 25, 293-315.

Schaufeli, W. B., \& Bakker, A. B. (2014). Defining and measuring work engagement: bringing clarity to the concept. In A. B. Bakker \& M. P. Leiter (Eds.), Work engagement: A handbook of essential theory and research (pp. 10-24). New York, NY: Psychology Press.

Soennentag, S., Demerouti, E., Mojza, E. J., \& Bakker, A. (2012). Reciprocal relations between recovery and work engagement: The moderating role of job stressors. American Psychological Associations, 97(4), 842-853.

Subramony, M., Krause, N., Norton, J., \& Burns, G. N. (2008). The relationship between human resource investments and organizational performance: A firm-level examination of equilibrium theory. Journal of Applied Psychology, 93, 778-788. doi:10.1037/00219010.93.4.778.

Virga, D., Horga, A., \& Iliescu, D. (2015). Work-life imbalance as a moderator in the relationship between resources and work engagement. Journal of Personnel Psychology, 14(2), 80-90.

Xanthopoulou, D., Bakker, A. B., Demerouti, E., \& Schaufeli, W. B. (2007). The role of personal resources in the job demands-resources model. International Journal of Stress Management, 14, 121-141. 